\title{
Idiosyncratic Volatility and the Intertemporal Capital Asset Pricing Model
}

\author{
Gang $\mathbf{L i}^{\dagger}$ \\ University of Toronto
}

\begin{abstract}
:
When the true asset pricing model cannot be identified, the idiosyncratic volatility obtained from a misspecified model contains information of the hedge portfolio in Merton's (1973) ICAPM. Empirically, I find that from 1815 to 2018, more than two centuries, neither equalweighted idiosyncratic volatility (EWIV) nor value-weighted idiosyncratic volatility (VWIV) can forecast stock market returns. However, EWIV and VWIV when applied together are strong predictors of stock market returns over short- and long-term horizons. The explanatory power is economically significant with an out-of-sample forecasting $R^{2}$ around $1 \%$ for one month and $12 \%$ for one year. This finding suggests that EWIV and VWIV together are linked to state variables that capture time-varying investment opportunities. I argue that the combination of EWIV and VWIV is a proxy for the conditional covariance risk in the ICAPM. I revisit the debate between Goyal and Santa-Clara (2003) and Bali, Cakici, Yan, and Zhang (2005) and reconcile their mixed findings between aggregate idiosyncratic volatility and future stock market returns.
\end{abstract}

JEL classification: G12, G13, G14, G17

Keywords: idiosyncratic volatility, stock market variance, conditional covariance, time-series stock return predictability, expected stock returns, intertemporal capital asset pricing model, economic state variable, risk-return tradeoff

\footnotetext{
$\dagger$ Rotman School of Management, University of Toronto,
} 


\section{$10^{\text {th }}$ International Conference on Modern Research in}

\section{MANAGEMENT, ECONOMICS and ACCOUNTING}

\section{0-22 March, $2020 \quad$ Berlin, GERMANY}

\section{Introduction}

Goyal and Santa-Clara (2003) found that equal-weighted idiosyncratic volatility (EWIV) can positively forecast future stock market returns, suggesting that idiosyncratic risk matters for asset pricing. The finding, however, is criticized by several studies. For example, Bali et al (2005) and Wei and Zhang (2005) argue that this empirical finding is attributed to liquidity premium, small-stock bias, and sample-specific period. That is, when looking at a more recent period, EWIV is unable to predict aggregate stock returns. However, the value-weighted idiosyncratic volatility (VWIV) is negatively related to future stock market returns, although the significance is not as strong as other existing predictors. ${ }^{1}$ The difference in forecasting performance between EWIV and VWIV is confusing and ambiguous in the literature. To date, existing studies do not find consistent return predictability by aggregate idiosyncratic volatility. As a result, how aggregate idiosyncratic volatility affects asset prices remains unclear, especially for the time-series return predictability. I revisit this topic and provide an alternative explanation as to why existing studies obtain mixed conclusions. I show that aggregate idiosyncratic volatility, in fact, can be used to forecast stock market returns at both high and low frequencies.

Theoretically, if the CAPM holds, idiosyncratic volatility is related to neither time series nor cross-section of stock returns. Levy (1978), Campbell, Lettau, Malkiel, and Xu (2001), and Malkiel and $\mathrm{Xu}$ (2001) claim that if investors hold undiversified portfolios, the expected return of any asset will be positively linked to idiosyncratic volatility. Their models imply that when investors' portfolios are less diversified, aggregate idiosyncratic volatility should be positively related to future stock market returns in time series. However, recent empirical evidence has not consistently supported this prediction. While most of the previous studies focus on explaining the cross-sectional effect of idiosyncratic volatility with much success, ${ }^{2}$ the time-

\footnotetext{
${ }^{1}$ For example, the relevant papers include Guo and Savickas (2008), Chen and Petkova (2012), and Pollet and Wilson (2010). However, no papers document that VWIV has return predictive power longer than one quarter.

2 The typical papers include: Ang, Hodrick, Xing, and Zhang (2006), Brand, Brav, Graham, and Kumar (2009), Campbell and Taksler (2003), Fu (2009), Chen and Petkova (2012), Cao and Han (2016), Herskovic, Kelly, Lustig, and Nieuwerburgh (2016).
} 
$10^{\text {th }}$ International Conference on Modern Research in MANAGEMENT, ECONOMICS and ACCOUNTING

\section{0-22 March, 2020 Berlin, GERMANY}

series effect of aggregate idiosyncratic volatility is still unclear and less explored. My research aims to fill this gap.

In this paper, I first document a novel finding that when running a bivariate regression of aggregate stock returns on EWIV and VWIV, both variables express strong and significant forecasting capacities for stock market returns. The explanatory power is economically significant with an out-of-sample $R^{2}$ around $1 \%$ for one month and $12 \%$ for one year. EWIV is positively related to future stock market returns (consistent with Goyal and Santa-Clara, 2003), while the coefficient of VWIV remains negative (consistent with Guo and Savickas, 2008; Pollet and Wilson, 2010). The empirical findings are robust for various concerns of the predictive power of aggregate idiosyncratic volatility in the literature such as small-stock effect, sample-specific periods, market liquidity premium, business-cycle conditions, and predictor persistency. ${ }^{3}$ The significance of both coefficients cannot be explained by multicollinearity because, otherwise both coefficients would be insignificant (smaller t-statistic) with a high- $R^{2}$ (larger F-statistic) regression. Statistically, the combined effect is more consistent with the omitted variable issue, which leads to estimation biases of univariate OLS regression.

Theoretically, the combined effect of EWIV and VWIV can be understood through Merton's (1973) ICAPM. In his analysis, when the investor dynamically decides her optimal portfolio position, and if there exist certain state variables which can forecast future investment opportunities, the expected return of any asset (including the market portfolio) is determined by both its covariance with the market portfolio and with the innovation of the state variables (Hedegaard and Hodrick, 2014). While the market portfolio is easy to observe, the state variables are difficult to detect and thus to value (Rossi and Timmermann, 2015). Given that not all state variables are identifiable and that econometricians use a misspecified asset pricing model, the residual terms will consist of multiple systematic components, some of which are driven by the missed state variables and thus related to equity risk premium. I show in theory that although a single aggregate idiosyncratic variance could not capture the covariance risk in the ICAPM, a combination between two types of weighted average idiosyncratic variance is able to pin down the conditional covariance risk, and therefore is linked to stock market returns.

\footnotetext{
${ }^{3}$ More information can be found in Bali, Cakici, Yan, and Zhang (2005), Wei and Zhang (2007), Amihud,Hurvich, and Wang (2008), and Bekaert, Hodrick, and Zhang (2012).
} 


\section{$10^{\text {th }}$ International Conference on Modern Research in}

\section{MANAGEMENT, ECONOMICS and ACCOUNTING}

\section{0-22 March, 2020 Berlin, GERMANY}

The remainder of the paper is organized as follows. Section 2 derives the theoretical framework of the relationship between the combination of EWIV and VWIV and conditional covariance risk in the ICAPM. Section 3 provides both in-sample and out-of-sample time-series empirical evidence. Section 4 concludes the paper.

\section{Theoretical Motivation}

The derivation begins with the discrete-time version of Merton's ICAPM. By analyzing the dynamic optimal portfolio choice of the representative agent, Merton (1973) suggests the expression of the conditional expected return on asset $i$ as:

$$
E_{t}\left(R_{i, t+1}\right)=\gamma_{M} \operatorname{Cov}_{t}\left(R_{i, t+1}, R_{M, t+1}\right)+\sum_{k=1}^{K} \gamma_{k} \operatorname{Cov}_{t}\left(R_{i, t+1}, \Delta Z_{k, t+1}\right), \quad i=1, \ldots, N,
$$

where

$R_{i, t+1}$ is the excess return (rates of return minus a risk-free rate) for asset $i$,

$R_{M, t+1}=\sum_{i=1}^{N} w_{i, t} R_{i, t+1}$ is the market excess return, where $w_{i, t}$ is the market portfolio's weight for asset $i$,

$Z_{k, t+1}$ stands for certain state variable $k$, which contains information about future investment opportunities,

$\gamma_{M}$ is the relative risk aversion of the representative agent, assumed to be constant,

$\gamma_{k}$ is the weighted average across investors of their state-variable aversions, assumed to be constant as well,

$E_{t}$ is the conditional expectation operator on information at time $t$,

$\operatorname{Cov}_{t}$ is the conditional covariance operator on information at time $t$.

Equation (1) has been deduced in many papers such as Merton (1973), Long (1974), and Cox, Ingersoll, and Ross (1985). The ICAPM predicts that the expected return on asset $i$ is determined by not only its covariance with the market portfolio but also its covariance with the innovation of certain state variables, which are linked to future investment opportunities (e.g., aggregate stock returns or volatility). Equation (1) can be used to derive the conditional equity risk premium: 


\section{$10^{\text {th }}$ International Conference on Modern Research in}

\section{MANAGEMENT, ECONOMICS and ACCOUNTING}

\section{0-22 March, $2020 \quad$ Berlin, GERMANY}

$$
E_{t}\left(R_{M, t+1}\right)=\gamma_{M} \operatorname{Var}_{t}\left(R_{M, t+1}\right)+\sum_{k=1}^{K} \gamma_{k} \operatorname{Cov}_{t}\left(R_{M, t+1}, \Delta Z_{k, t+1}\right) \text {, }
$$

where $\operatorname{Var}_{t}$ stands for the conditional variance operator on information at time $t$. For simplicity, I will use $\mu$ to denote the expected return and $\sigma^{2}$ to denote the (co)variance term for the rest of the derivations. $\mu_{i, t}, \mu_{M, t}, \mu_{H, t}\left(\sigma_{i, t}, \sigma_{M, t}, \sigma_{H, t}\right)$ are the conditional expected excess return (volatility) of asset $i$, the market portfolio, and the hedge portfolio at time $t . \sigma_{i M, t}, \sigma_{i H, t}, \sigma_{M H, t}$ stand for the covariance between any two of them.

The ICAPM states that the conditional equity risk premium is determined not only by the conditional variance of the market portfolio but also by the conditional covariance of the market portfolio with the innovation of the state variables. Equation (2) can be simplified to a two-factor model by creating a new giant covariance term including all state variables:

$$
\mu_{M, t}=\gamma_{M} \sigma_{M, t}^{2}+\operatorname{Cov}_{t}\left(R_{M, t+1}, \sum_{k=1}^{K} \gamma_{k} \Delta Z_{k, t+1}\right) .
$$

In practice, since the state variable $\left(Z_{K}\right)$ is not tradeable, people often project the innovation of the state variable to a factor mimicking portfolio, namely a hedge portfolio, which is correlated with future investment opportunities. Based on the two traded portfolios, the corresponding conditional equity risk premium can be written as:

$$
\mu_{M, t}=\gamma_{M} \sigma_{M, t}^{2}+\gamma_{H} \sigma_{M H, t}
$$

Assuming rational expectations, the realized return generating process can be expressed as the beta representation:

$$
R_{i, t+1}=\beta_{i M, t}\left(\mu_{M, t}+\varepsilon_{M, t+1}\right)+\beta_{i H, t}\left(\mu_{H, t}+\varepsilon_{H, t+1}\right)+\varepsilon_{i, t+1}
$$

where $\varepsilon_{M, t+1}, \varepsilon_{H, t+1}$, and $\varepsilon_{i, t+1}$ are exogenous shocks for the market portfolio, the hedge portfolio, and asset $i$. The cross-sectional distribution of the idiosyncratic shock is assumed to be normal and stable over time (Ferson, Kandel, and Stambaugh, 1987). It is worth noting that the risk exposure of asset $i$ to the market portfolio is affected by the extra covariance term in the ICAPM (Merton, 1990, P.390). While the market portfolio can easily be observed, the hedge portfolio is difficult to estimate. Assume that econometricians only use the CAPM as the asset pricing model,

$$
R_{i, t+1}=b_{i M, t}\left(\mu_{M, t}+\varepsilon_{M, t+1}\right)+\eta_{i, t+1}
$$




\section{$10^{\text {th }}$ International Conference on Modern Research in}

\section{MANAGEMENT, ECONOMICS and ACCOUNTING}

\section{0-22 March, $2020 \quad$ Berlin, GERMANY}

where $b_{i M, t}=\frac{\sigma_{i M, t}}{\sigma_{M, t}^{2}}$ is the misspecified risk exposures; $\eta_{i, t+1}$ is the misspecified idiosyncratic shock for asset $i$ under the CAPM. I first show that the second conditional moments of the misspecified firm idiosyncratic shock can be expressed as a combination of conditional variance of the hedge portfolio and the conditional covariance between the market portfolio and the hedge portfolio.

Proposition 1. Suppose that the true conditional asset pricing model follows Merton's ICAPM defined in (5), but econometricians use the conditional CAPM as the asset pricing model defined in (6). The second conditional moment of the misspecified firm idiosyncratic shock $\eta_{i, t+1}$ is given by:

$$
\operatorname{Var}_{t}\left(\eta_{i, t+1}\right)=\beta_{i H, t} b_{i H, t} \sigma_{H, t}^{2}+\beta_{i H, t} b_{i M, t} \sigma_{M H, t}+\sigma_{\varepsilon_{i}, t}^{2},
$$

where

$$
\left\{\begin{array}{l}
\beta_{i M, t}=\frac{\sigma_{i M, t} \sigma_{H, t}^{2}-\sigma_{i H, t} \sigma_{M H, t}}{\sigma_{H, t}^{2} \sigma_{M, t}^{2}-\sigma_{M H, t}^{2}} \\
\beta_{i H, t}=\frac{\sigma_{i H, t} \sigma_{M, t}^{2}-\sigma_{i M, t} \sigma_{M H, t}}{\sigma_{H, t}^{2} \sigma_{M, t}^{2}-\sigma_{M H, t}^{2}}
\end{array}, \quad\left\{\begin{array}{l}
b_{i M, t}=\frac{\sigma_{i M, t}}{\sigma_{M, t}^{2}} \\
b_{i H, t}=\frac{\sigma_{i H, t}}{\sigma_{H, t}^{2}}
\end{array} .\right.\right.
$$

Proofs are provided in the Appendix. Proposition 1 shows that the misspecified idiosyncratic variance contains at least two common components, but only one of them (i.e., $\sigma_{M H, t}$ ) is related to the conditional equity risk premium. Corollary 1.1 below proves how two types of different weighted-average idiosyncratic variance can capture the conditional covariance in Merton's ICAPM, thus are linked to stock market returns. In my study, I use equal-weighted average idiosyncratic variance (EWIV) and value-weighted average idiosyncratic variance (VWIV) as an example. Theoretically, the weighting schemes are not necessarily restricted to this choice.

Corollary 1.1 Suppose that the true conditional asset pricing model follows Merton's ICAPM defined in (5), but econometricians use the conditional CAPM as the asset pricing model defined in (6). The conditional variance of the hedge portfolio and the conditional covariance between the market portfolio and the hedge portfolio are given by

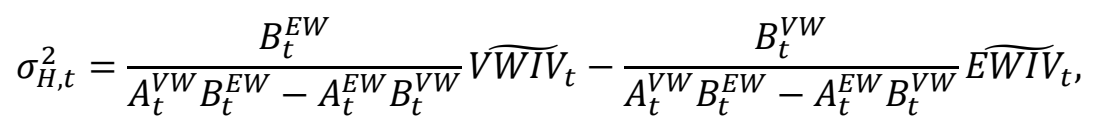

$$
\begin{aligned}
& \sigma_{M H, t}=\frac{A_{t}^{V W}}{A_{t}^{V W} B_{t}^{E W}-A_{t}^{E W} B_{t}^{V W}} \widetilde{E W I V}_{t}-\frac{A_{t}^{E W}}{A_{t}^{V W} B_{t}^{E W}-A_{t}^{E W} B_{t}^{V W}} \widetilde{V W I V}{ }_{t}
\end{aligned}
$$


where

$$
\begin{aligned}
& \left\{\begin{array}{l}
A_{t}^{E W}=\sum_{i=1}^{N_{t}} \frac{1}{N_{t}} \beta_{i H, t} b_{i H, t} \\
A_{t}^{V W}=\sum_{i=1}^{N_{t}} w_{i, t} \beta_{i H, t} b_{i H, t}
\end{array},\left\{\begin{array}{l}
B_{t}^{E W}=\sum_{i=1}^{N_{t}} \frac{1}{N_{t}} \beta_{i H, t} b_{i M, t} \\
B_{t}^{V W}=\sum_{i=1}^{N_{t}} w_{i, t} \beta_{i H, t} b_{i M, t}
\end{array}, \quad\left\{\begin{array}{l}
E W I V_{t}=\sum_{i=1}^{N_{t}} \frac{1}{N_{t}} \operatorname{Var}_{t}\left(\eta_{i, t+1}\right) \\
V W I V_{t}=\sum_{i=1}^{N_{t}} w_{i, t} \operatorname{Var}_{t}\left(\eta_{i, t+1}\right)
\end{array}\right.\right.\right. \\
& \left\{\begin{array}{l}
\Omega_{t}^{\mathrm{EW}}=\sum_{i=1}^{N_{t}} \frac{1}{N_{t}} \sigma_{\varepsilon_{i}, t}^{2} \\
\Omega_{t}^{V W}=\sum_{i=1}^{N_{t}} w_{i, t} \sigma_{\varepsilon_{i}, t}^{2}
\end{array}, \quad\left\{\begin{array}{l}
E \widehat{E I V}_{t}=E W I V_{t}-\Omega_{t}^{E W} \\
V \overline{W I V}_{t}=V W I V_{t}-\Omega_{t}^{V W}
\end{array}\right.\right.
\end{aligned}
$$

Proofs and corresponding assumptions are provided in the Appendix. Since the weighting schemes are not perfectly linearly correlated (i.e., $A_{t}^{V W} B_{t}^{E W}-A_{t}^{E W} B_{t}^{V W} \neq 0$ ). The solution exists and is unique. Both the conditional variance of the hedge portfolio and the conditional covariance of the market portfolio with the hedge portfolio are a linear combination of EWIV and VWIV. Empirically, the second conditional moment of $\eta_{i, t+1}$ can be estimated by the standard deviation of the realized idiosyncratic shocks from the CAMP using the daily returns within each month:

$$
\widehat{\operatorname{Var}}_{t}\left(\eta_{i, t+1}\right)=\frac{1}{21} \sum_{s=0}^{21}\left(R_{i, t-s}-\hat{b}_{i M, t} R_{M, t-s}\right)^{2}
$$

Because both $\sigma_{H, t}^{2}$ and $\sigma_{M H, t}$ are time-varying and because only $\sigma_{M H, t}$ matters for the conditional equity risk premium, a single aggregate idiosyncratic variance (EWIV or VWIV) is a noisy proxy for $\sigma_{M H, t}$, and therefore is inconsistent in its performance forecasting future stock market returns. This is why previous research obtains mixed empirical findings of the predictive power of aggregate idiosyncratic variance.

Proposition 2 Suppose that the true conditional asset pricing model follows Merton's ICAPM defined in (5), but econometricians use the conditional CAPM as the asset pricing model defined in (6). The conditional equity risk premium can be expressed as:

$$
\mu_{M, t}=\gamma_{M} \sigma_{M, t}^{2}+\gamma_{H} \sigma_{M H, t}=\gamma_{M} \times \sigma_{M, t}^{2}+C_{t} \times \widetilde{E W I V}_{t}-D_{t} \times \widetilde{V W I V}_{t}
$$

where 
$10^{\text {th }}$ International Conference on Modern Research in MANAGEMENT, ECONOMICS and ACCOUNTING

\section{0-22 March, 2020} Berlin, GERMANY

$$
C_{t}=\frac{\gamma_{H} A_{t}^{V W}}{A_{t}^{V W} B_{t}^{E W}-A_{t}^{E W} B_{t}^{V W}}, \quad D_{t}=\frac{\gamma_{H} A_{t}^{E W}}{A_{t}^{V W} B_{t}^{E W}-A_{t}^{E W} B_{t}^{V W}} .
$$

Proofs and corresponding assumptions are given in the Appendix. Note that $\sigma_{M H, t}$ is replaced by the combination of $\widetilde{E W I V}$ and $\widetilde{V W I V}$, since the latter are identifiable. As to the coefficients, if $A_{t}^{E W}$ and $A_{t}^{V W}$ have the same sign, the coefficients of EWIV and VWIV are supposed to be opposite each other.

\section{Time-Series Empirical Evidence}

\subsection{Data, Variable, and Summary Statistics}

From 1926 to 2018, for each stock at the end of each month, I use the past 30-day return observations to fit the CAPM model. The data of stock returns, market capitalization, share code, and exchange code are obtained from the CRSP. The stock market excess return (MKTRF) is downloaded from Kenneth French's website. The number of return observations within each month should be greater than 20 . The idiosyncratic volatility of each stock is then defined as the standard deviation of the residuals from the benchmark model. ${ }^{4}$ The valueweighted idiosyncratic volatility (VWIV) and equal-weighted idiosyncratic volatility (EWIV) are simply obtained by taking the cross-sectional average based on either market-capitalization weights at the end of the previous month or equal weights. When constructing aggregate idiosyncratic volatility, I include all available securities traded in the U.S. stock exchanges, so that it is closer to the market portfolio. ${ }^{5}$

In order to construct the sample before 1926, I collect monthly observations including stock price, stock return, and market capitalization from the Global Financial Data (GFD), which provides U.S. stock data beginning from 1790 . The monthly firm idiosyncratic volatility before 1926 is estimated using a 48-month rolling window of return observations to fit the CAPM. The market excess returns between 1871 to 1925 are obtained from Amit Goyal's website.

\footnotetext{
${ }^{4}$ The empirical results are robust if I use other types of definitions such as total volatility proposed by French et al (1987), idiosyncratic volatility based on different benchmarks (e.g., Fama-French three/five-factor model) and frequencies (e.g., daily or monthly), and total variance used in Chen and Petkova (2012).

${ }^{5}$ The empirical results are robust if I only include the common stocks.
} 


\section{$10^{\text {th }}$ International Conference on Modern Research in}

\section{MANAGEMENT, ECONOMICS and ACCOUNTING}

\section{0-22 March, $2020 \quad$ Berlin, GERMANY}

From 1815 to 1870 , there were no liquid monthly short-term government securities (Golez and Koudijs, 2018). Therefore, I use the raw stock market returns between 1815 and 1870 . The data is obtained from G.William Schwert's website (Schwert, 1990). The value-weighted idiosyncratic volatility (VWIV) and equal-weighted idiosyncratic volatility (EWIV) are simply derived by taking the cross-sectional average based on either market-cap weights at the end of the previous month or equal weights. When constructing aggregate idiosyncratic volatility, I include all available securities traded in the U.S. stock exchanges with a stock price greater than $\$ 1$. As a comparison, I also estimate the stock market volatility (SMV) based on the past 30-day daily return observations of MKTRF.

\section{[Insert Figure 1]}

Since the data of CRSP before 1963 is subject to quality issues (Shumway, 1997), the main sample period is from 1963 to 2018. The empirical results with longer periods from 1815 to 1962 are provided as robustness checks.

\section{[Insert Table 1]}

Figures 1 show that EWIV is always higher than VWIV, which is consistent with previous findings in the literature that small firms' volatilities are on average higher than big firms' volatilities. In the meantime, SMV shares a lower correlation with either EWIV or VWIV. All the volatility measures shoot up during the recession periods and revert back to the normal level thereafter. As expected, EWIV and VWIV are highly correlated with each other (correlation equals to 0.893). However, one can see that EWIV and VWIV also perform differently sometimes. For example, EWIV shoots up much higher than VWIV during recessions. The divergence between EWIV and VWIV supports the assumption that the variance and covariance of the hedge portfolio are time-varying.

\subsection{In-Sample Empirical Evidence}

The most commonly used multi-period predictive regression follows Fama and French (1988, 1989):

$$
\sum_{k=1}^{K} \frac{r_{t+k}}{K} \equiv r_{t, t+K}=a+b \times X_{t}+\epsilon_{t, t+K}
$$


$10^{\text {th }}$ International Conference on Modern Research in

\section{MANAGEMENT, ECONOMICS and ACCOUNTING}

\section{0-22 March, 2020 Berlin, GERMANY}

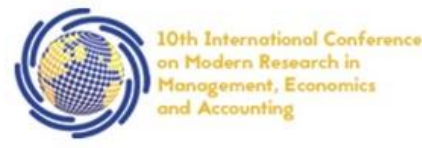

Similarly, the bivariate regression can be written as:

$$
r_{t, t+K}=a+b_{1} \times X_{1, t}+b_{2} \times X_{2, t}+\epsilon_{t, t+K}
$$

where $r_{t+k}$ is the value-weighted market excess return in logarithm (MKTRF) at time $t+k$ obtained from Kenneth French's Website; $X_{t}$ is the predictor variable of interest; $K$ stands for the forecast horizon (number of months ahead). I run monthly predictive regressions with $K$ equal to $1,3,6,12$, and 24 months. When $K>1$, I correct the serial correlation and conditional heteroscedasticity using the Newey-West correction with $K-1$ lags (Newey and West, 1987). The hypothesis testing is $H_{0}: b=0, H_{1}: b \neq 0$. When running regressions, to make the coefficients comparable, I scale all independent variables to have zero mean and one standard deviation.

Since there are multiple predictors in the regressions and both of them are highly correlated and persistent, the hypothesis test from OLS might be subject to estimation biases. Amihud, Hurvich, and Wang (2008) propose an alternative hypothesis-testing method for multiplepredictor regressions in small samples. Their approach, the multi-predictor augmented regression method (mARM), shows better performance to reject the null hypothesis of no predictive power than those of OLS and bootstrapping method. Therefore, I also conduct their test and provide the corresponding mARM statistics as a robustness check for the conclusion. The corresponding mARM statistics are provided in Table 2.

\section{[Insert Table 2]}

Table 2 provides convincing evidence that although neither EWIV nor VWIV is able to predict stock market returns, EWIV and VWIV jointly are strong predictors of aggregate stock returns. The in-sample one-month and one-year $R^{2}$ are around $1 \%$ and $14 \%$ respectively.

To investigate whether the combination of EWIV and VWIV is only a proxy for any existing predictor in the literature, I run the multiple regressions with the combination of EWIV and VWIV and each of the classic predictors found by other papers. The controlling variables include: 22 predictors based on Goyal and Welch (2008) from Amit Goyal's website, stock market volatility (SMV; Guo and Savickas, 2008), variance risk premium (VRP; Bollerslev, Tauchen, and Zhou, 2009), lower-bound equity premium (SVIX; Martin, 2017), average correlation (Pollet and Wilson, 2010), asset wealth (CAY; Lettau and Ludvigson, 2001), 


\section{$10^{\text {th }}$ International Conference on Modern Research in}

\section{MANAGEMENT, ECONOMICS and ACCOUNTING}

\section{0-22 March, 2020 Berlin, GERMANY}

aggregate stock illiquidity (ILIQ; Chen, Eaton, and Paye, 2018), investor sentiment (Wurgler and Baker, 2007), aggregate short interest (SII; Rapach, Ringgenberg, and Zhou, 2016), and aggregate implied volatility spread (IVS; Han and Li, 2017). The regression specification is given by:

$$
r_{t, t+K}=a+b_{1} \times E W I V_{t}+b_{2} \times V W I V_{t}+b_{3} \times X_{i, t}+\epsilon_{t, t+K}
$$

\section{[Insert Table 3]}

Table 3 shows that after controlling for those selected predictors, EWIV and VWIV retain the significance at all forecast horizons. The coefficients of EWIV and VWIV in Table 3 are about the same as the corresponding ones in the univariate regressions in Table 2. Furthermore, when stock market volatility is included in the regression, it shows significant positive relation with stock market returns, thus supporting the positive risk-return tradeoff.

\subsection{Out-of-Sample Performance}

To alleviate concerns about overfitting and finite sample biases, I conduct out-of-sample tests by separating the data sample (1963 2018) into two parts: 1963 1980 as the in-sample estimation period and 1981 2018 as the out-of-sample performance evaluation period. Starting in January 1981, I run various predictive regressions each month using historical data from January 1963 and then compare the out-of-sample forecast errors (i.e., differences between the realized market returns and the predicted returns) with those from the benchmark model (i.e., historical average). ${ }^{6}$ The statistical test of equal predictive accuracy in nested models is based on Clark and West (2007). The regression details are given by:

$$
\begin{gathered}
\begin{cases}r_{t, t+K}=\alpha+\beta \times x_{t}+\epsilon_{t, t+K}, & t=1, \ldots, T_{0}-K \\
\hat{r}_{t, t+K}=\hat{\alpha}+\hat{\beta} \times x_{t}, & t=T_{0}, \ldots, T,\end{cases} \\
\text { Benchmark: } \quad r_{t, t+K}^{B}=\frac{1}{t-K} \sum_{s=1}^{t-K} r_{s, s+K}, \quad t=T_{0}, \ldots, T,
\end{gathered}
$$

where $K$ is the forecast horizon, $r_{t, t+K}$ is the market excess return from time $t$ to $t+K, x_{t}$ is the value of the predictor at time $t ; \hat{r}_{t, t+K}$ is the forecasted return based on $x_{t}$ from the recursive

\footnotetext{
${ }^{6}$ Similar out-of-sample tests are used by Campbell and Thompson (2008), Goyal and Welch (2008), and Rapach et al. (2010).
} 


\section{$10^{\text {th }}$ International Conference on Modern Research in}

\section{MANAGEMENT, ECONOMICS and ACCOUNTING}

\section{0-22 March, 2020 \\ Berlin, GERMANY}

regression. The out-of-sample $R^{2}$ statistic is defined as 1 minus the ratio of mean squared forecast error of the larger model to that of the benchmark model:

$$
\begin{gathered}
M S F E_{1}=\frac{1}{T-T_{0}} \sum_{t=T_{0}}^{T}\left(r_{t, t+K}-\hat{r}_{t, t+K}\right)^{2} ; M S F E_{0}=\frac{1}{T-T_{0}} \sum_{t=T_{0}}^{T}\left(r_{t, t+K}-r_{t, t+K}^{B}\right)^{2}, \\
R_{O S}^{2}=1-\left(\frac{M S F E_{1}}{M S F E_{0}}\right)
\end{gathered}
$$

where $\left(T-T_{0}\right)$ is the number of out-of-sample evaluation periods. I test the hypothesis $H_{0}: M S F E_{0} \leq M S F E_{1}$ vs. $H_{1}: M S F E_{0}>M S F E_{1}$, or equivalently $H_{0}: R_{O S}^{2} \leq 0$ vS. $H_{1}: R_{O S}^{2}>$ 0. Following the Clark and West (2007) test for nested models, I adjust the point estimate of the difference between two MSFEs for the noise associated with the larger model's forecast and define

$$
\hat{f}_{t, t+K}=\left(r_{t, t+K}-r_{t, t+K}^{B}\right)^{2}-\left[\left(r_{t, t+K}-\hat{r}_{t, t+K}\right)^{2}-\left(r_{t, t+K}^{B}-\hat{r}_{t, t+K}\right)^{2}\right]
$$

The test of equal predictive accuracy is conducted by regressing $\hat{f}_{t, t+K}$ on a constant and using the resulting $z$-statistic for a zero coefficient. The null hypothesis is rejected (equivalent to $R_{O S}^{2}$ as statistically significant) if this statistic is greater than 1.282 (for a one-sided test at $10 \%$ confidence), 1.645 (for a one-sided test at 5\% confidence), or 2.334 (for a one-sided test at $1 \%$ confidence). When forecast horizon $K$ is greater than one, I adjust for serial correlation and conditional heteroskedasticity using the Newey-West correction with $K-1$ lags.

\section{[Insert Table 4]}

Table 4 Panel A reports the $R_{O S}^{2}$ statistics for various predictors and forecast horizons. The out-of-sample $R_{O S}^{2}$ for the combination of EWIV and VWIV is as high as $0.64 \%$ for one-month ahead, $5.46 \%$ for six-month ahead, and $11.90 \%$ for a one-year ahead forecast horizon. All of them are statistically significant at the $1 \%$ level.

Time-series predictability of stock market returns has important implications for market timing by guiding investors to optimally allocate wealth between stock investments and a risk- 


\section{$10^{\text {th }}$ International Conference on Modern Research in}

\section{MANAGEMENT, ECONOMICS and ACCOUNTING}

\section{0-22 March, 2020 \\ Berlin, GERMANY}

free asset. ${ }^{7}$ I consider a mean-variance-utility investor who allocates wealth between the market portfolio and T-bill. Given an investment horizon of $K$ periods, her optimal weight on the market portfolio is:

$$
w_{t, t+K}=\frac{1}{\gamma} \frac{\hat{r}_{t, t+K}}{\hat{\sigma}_{t, t+K}^{2}},
$$

where $\hat{r}_{t, t+k}$ is conditional expected market excess return (i.e., forecast based on a predictor) given by equation (15). The $\hat{\sigma}_{t, t+K}^{2}$ is estimated using the variance of the past five-year historical returns, and the relative risk aversion $\gamma$ is set to be 3 . The portfolio is rebalanced every month. The corresponding Sharpe ratio of the investor's optimal portfolio is given by:

$$
S R=\frac{R_{P}}{\sigma_{p}}
$$

where $R_{P}$ and $\sigma_{p}$ are the mean and the standard deviation of the portfolio return. The average utility gain or the certainty equivalent return (CER) is computed as:

$$
C E R=R_{P}-0.5 \gamma \sigma_{p}^{2}
$$

To gauge the economic benefit of a predictor to the mean-variance investor, I compare the CER above associated with the optimal portfolio based on the forecasts provided by the predictor to $\overline{C E R}$, the certainty equivalent return of a benchmark portfolio formed based on the average return and standard deviation estimated from historical returns. The difference is defined as the CER gain:

$$
C E R \text { Gain }=C E R-\overline{C E R} \text {. }
$$

Table 4 Panel B compares the economic value of using out-of-sample forecasts provided by each predictor to form the optimal portfolio. Consistent with the results in Table 4 Panel A, EWIV and VWIV together outperform other predictors at horizons from one month to two years.

\footnotetext{
${ }^{7}$ The implication of out-of-sample return prediction is documented in for example Kandel and Stambaugh (1996), Campbell and Thompson (2008), Rapach, Strauss, and Zhou (2010), and Ferreira and Santa-Clara (2011).
} 


\section{$10^{\text {th }}$ International Conference on Modern Research in}

\section{MANAGEMENT, ECONOMICS and ACCOUNTING}

\section{0-22 March, 2020 \\ Berlin, GERMANY}

\section{Conclusion}

The importance of idiosyncratic volatility is an essential topic in asset pricing. While most of the previous research focuses on cross-sectional studies of idiosyncratic volatility, this paper examines asset pricing implications of aggregate idiosyncratic volatility. I contribute to the literature that aggregate idiosyncratic volatility in fact matters to asset pricing in both time series and cross-section. Empirically, I document that equal-weighted idiosyncratic volatility (EWIV) and value-weighted idiosyncratic volatility (VWIV) jointly are strong predictors of aggregate stock returns in both short- and long-term horizons. I argue that these findings can be understood under the framework of Merton's (1973) ICAPM that EWIV and VWIV when applied together are a proxy for the conditional covariance between the market portfolio and the hedge portfolio. Based on this framework, I revisit two debates regarding idiosyncratic volatility and tail risk in the literature and provide new insights and reconciliations pertaining to their mixed findings

\section{References:}

Amihud, Y., Hurvich, C. M., and Wang, Y. (2008). Multiple-predictor regressions: Hypothesis testing. Review of Financial Studies, 22(1), 413-434.

Ang, A., Hodrick, R. J., Xing, Y., and Zhang, X. (2006). The cross-section of volatility and expected returns. Journal of Finance, 61(1), 259-299.

Baker, M., Greenwood, R., and Wurgler, J. (2003). The maturity of debt issues and predictable variation in bond returns. Journal of Financial Economics, 70(2), 261-291.

Bali, T. G., Cakici, N., Yan, X., and Zhang, Z. (2005). Does idiosyncratic risk really matter? Journal of Finance, 60(2), 905-929.

Bekaert, G., Hodrick, R. J., and Zhang, X. (2012). Aggregate idiosyncratic volatility. Journal of Financial and Quantitative Analysis, 47(6), 1155-1185.

Bollerslev, T., Tauchen, G., and Zhou, H. (2009). Expected stock returns and variance risk premia. Review of Financial Studies, 22(11), 4463-4492.

Campbell, J. Y., Lettau, M., Malkiel, B. G., and Xu, Y. (2001). Have individual stocks become more volatile? An empirical exploration of idiosyncratic risk. Journal of Finance, 56(1), 1-43. 


\section{$10^{\text {th }}$ International Conference on Modern Research in}

\section{MANAGEMENT, ECONOMICS and ACCOUNTING}

\section{0-22 March, $2020 \quad$ Berlin, GERMANY}

Campbell, J. Y., and Thompson, S. B. (2008). Predicting excess stock returns out of sample: Can anything beat the historical average? Review of Financial Studies, 21(4), 1509-1531.

Campbell, J. Y., and Taksler, G. B. (2003). Equity volatility and corporate bond yields. Journal of Finance, 58(6), 2321-2350.

Cao, J., and Han, B. (2016). Idiosyncratic risk, costly arbitrage, and the cross-section of stock returns. Journal of Banking \& Finance, 73, 1-15.

Chen, Y., Eaton, G. W., and Paye, B. S. (2018). Micro (structure) before macro? The predictive power of aggregate illiquidity for stock returns and economic activity. Journal of Financial Economics, 130(1), 48-73.

Clark, T. E., and West, K. D. (2007). Approximately normal tests for equal predictive accuracy in nested models. Journal of Econometrics, 138(1), 291-311.

Cox, J. C., Ingersoll Jr, J. E., and Ross, S. A. (1985). An intertemporal general equilibrium model of asset prices. Econometrica: Journal of the Econometric Society, 363-384.

Fama, E. F., and French, K. R. (1988). Dividend yields and expected stock returns. Journal of Financial Economics, 22(1), 3-25.

Fama, E. F., and French, K. R. (1989). Business conditions and expected returns on stocks and bonds. Journal of Financial Economics, 25(1), 23-49.

Ferreira, M. A., and Santa-Clara, P. (2011). Forecasting stock market returns: The sum of the parts is more than the whole. Journal of Financial Economics, 100(3), 514-537.

Ferson, W. E., Kandel, S., and Stambaugh, R. F. (1987). Tests of asset pricing with time-varying expected risk premiums and market betas. The Journal of Finance, 42(2), 201-220.

Fu, F. (2009). Idiosyncratic risk and the cross-section of expected stock returns. Journal of Einancial Economics, 91(1), 24-37.

Ghysels, E., Santa-Clara, P., and Valkanov, R. (2005). There is a risk-return trade-off after all. Journal of Financial Economics, 76(3), 509-548.

Goyal, A., and Santa-Clara, P. (2003). Idiosyncratic risk matters! Journal of Finance, 58(3), 975-1007.

Goyal, A. and Welch, I. (2008). A comprehensive look at the empirical performance of equity premium prediction. Review of Financial Studies, 21(4), 1455-1508.

Guo, H., and Savickas, R. (2008). Average idiosyncratic volatility in G7 countries. Review of Financial Studies, 21(3), 1259-1296.

Han, B., and Li, G. (2017). Aggregate implied volatility spread and stock market returns. 


\section{$10^{\text {th }}$ International Conference on Modern Research in}

\section{MANAGEMENT, ECONOMICS and ACCOUNTING}

\section{0-22 March, $2020 \quad$ Berlin, GERMANY}

Hedegaard, E., and Hodrick, R. J. (2014). Measuring the Risk-Return Tradeoff with Time-Varying Conditional Covariances (No. w20245). National Bureau of Economic Research.

Ingersoll, J. E. (1987). Theory of financial decision making (Vol. 3). Rowman \& Littlefield.

Kandel, S., and Stambaugh, R. F. (1996). On the predictability of stock returns: an asset-allocation perspective. Journal of Finance, 51(2), 385-424.

Lo, A. W., and MacKinlay, A. C. (1988). Stock market prices do not follow random walks: Evidence from a simple specification test. Review of Financial Studies, 1(1), 41-66.

Lo, A. W., and Wang, J. (2006). Trading volume: Implications of an intertemporal capital asset pricing model. Journal of Finance, 61(6), 2805-2840.

Martin, I. (2017). What is the Expected Return on the Market? Quarterly Journal of Economics, 132(1), 367-433.

Malkiel, B. G., and Xu, Y. (2002). Idiosyncratic risk and security returns. University of Texas at Dallas (November 2002).

Merton, R. C. (1973). An intertemporal capital asset pricing model. Econometrica, 41(5), 867-887.

Merton, R. C., and Samuelson, P. A. (1990). Continuous-time finance.

Nelson, D. B. (1991). Conditional heteroskedasticity in asset returns: A new approach. Econometrica: Journal of the Econometric Society, 347-370.

Newey WK, and West KD (1987) A simple, positive semi-definite, heteroscedasticity and autocorrelation consistent covariance matrix. Econometrica 55(3):703-708.

Pollet, J. M., and Wilson, M. (2010). Average correlation and stock market returns. Journal of Financial Economics, 96(3), 364-380.

Rapach, D. E., Ringgenberg, M. C., and Zhou, G. (2016). Short interest and aggregate stock returns. Journal of Financial Economics, 121(1), 46-65.

Rapach, D. E., Strauss, J. K., and Zhou, G. (2010). Out-of-sample equity premium prediction: Combination forecasts and links to the real economy. Review of Financial Studies, 23(2), 821-862.

Rossi, A. G., and Timmermann, A. (2015). Modeling covariance risk in Merton's ICAPM. Review of Financial Studies, 28(5), 1428-1461.

Scruggs, J. T. (1998). Resolving the puzzling intertemporal relation between the market risk premium and conditional market variance: A two-factor approach. Journal of Finance, 53(2), 575-603. 


\section{$10^{\text {th }}$ International Conference on Modern Research in MANAGEMENT, ECONOMICS and ACCOUNTING}

\section{0-22 March, 2020}

\section{Berlin, GERMANY}

Wei, S. X., and Zhang, C. (2005). Idiosyncratic risk does not matter: A re-examination of the relationship between average returns and average volatilities. Journal of Banking \& Finance, 29(3), 603-621.

Schwert, G. W. (1990). Indexes of United States stock prices from 1802 to 1987 (No. w2985). Journal of Business, 63 (July 1990) 399-426

\begin{tabular}{|c|c|c|c|c|c|c|c|c|c|c|c|}
\hline \multicolumn{12}{|c|}{ Table 1. Summary Statistics of Monthly EWIV, VWIV, SMV, and MKTRF } \\
\hline \multirow[b]{2}{*}{ Variable } & \multirow[b]{2}{*}{ Mean } & \multirow[b]{2}{*}{ STD } & \multicolumn{5}{|c|}{ Autocorrelation at Lag (Number of Months) } & \multicolumn{4}{|c|}{ Pearson Correlation } \\
\hline & & & 1 & 3 & 6 & 12 & 24 & EWIV & VWIV & SMV & MKTRF \\
\hline \multicolumn{12}{|c|}{ Panel A. Time Period: 181501 to 187012} \\
\hline EWIV & 0.049 & 0.024 & 0.975 & 0.952 & 0.925 & 0.880 & 0.778 & 1.000 & & & \\
\hline VWIV & 0.040 & 0.018 & 0.893 & 0.835 & 0.752 & 0.679 & 0.560 & 0.853 & 1.000 & & \\
\hline SMV & 0.030 & 0.013 & 0.995 & 0.981 & 0.955 & 0.883 & 0.705 & 0.566 & 0.535 & 1.000 & \\
\hline MKTRF & 0.004 & 0.033 & 0.058 & 0.051 & 0.123 & 0.040 & -0.022 & 0.129 & 0.082 & 0.069 & 1.000 \\
\hline \multicolumn{12}{|c|}{ Panel B. Time Period: 187101 to 192512} \\
\hline EWIV & 0.064 & 0.011 & 0.949 & 0.897 & 0.845 & 0.760 & 0.569 & 1.000 & & & \\
\hline VWIV & 0.050 & 0.011 & 0.949 & 0.904 & 0.842 & 0.737 & 0.547 & 0.826 & 1.000 & & \\
\hline SMV & 0.032 & 0.005 & 0.987 & 0.950 & 0.884 & 0.734 & 0.489 & 0.529 & 0.307 & 1.000 & \\
\hline MKTRF & 0.002 & 0.033 & 0.285 & -0.001 & 0.040 & -0.045 & -0.031 & 0.116 & 0.038 & 0.073 & 1.000 \\
\hline \multicolumn{12}{|c|}{ Panel C. Time Period: 192601 to 196212} \\
\hline EWIV & 0.026 & 0.016 & 0.948 & 0.856 & 0.760 & 0.565 & 0.470 & 1.000 & & & \\
\hline VWIV & 0.021 & 0.012 & 0.935 & 0.808 & 0.654 & 0.401 & 0.360 & 0.959 & 1.000 & & \\
\hline SMV & 0.065 & 0.046 & 0.886 & 0.646 & 0.647 & 0.578 & 0.383 & 0.626 & 0.514 & 1.000 & \\
\hline MKTRF & 0.008 & 0.065 & 0.135 & -0.166 & -0.031 & -0.012 & 0.035 & 0.015 & 0.017 & -0.111 & 1.000 \\
\hline \multicolumn{12}{|c|}{ Panel D. Time Period: 196301 to 201812} \\
\hline EWIV & 0.027 & 0.008 & 0.970 & 0.876 & 0.777 & 0.693 & 0.520 & 1.000 & & & \\
\hline VWIV & 0.020 & 0.005 & 0.948 & 0.850 & 0.727 & 0.567 & 0.277 & 0.893 & 1.000 & & \\
\hline SMV & 0.038 & 0.023 & 0.672 & 0.480 & 0.357 & 0.234 & 0.054 & 0.443 & 0.457 & 1.000 & \\
\hline MKTRF & 0.005 & 0.044 & 0.072 & 0.022 & -0.051 & 0.028 & -0.012 & -0.016 & -0.045 & -0.299 & 1.000 \\
\hline
\end{tabular}

The table reports the descriptive statistics for the monthly time-series EWIV, VWIV, SMV, and MKTRF, as well as their correlations. The sample periods are separated based on data resources and quality. The data before 192601 is collected from Global Financial Data. The data after 192601 is collected from CRSP. Detailed descriptions of the variables and their constructions are provided in Section 3. 
$10^{\text {th }}$ International Conference on Modern Research in MANAGEMENT, ECONOMICS and ACCOUNTING

\begin{tabular}{|c|c|c|c|c|c|c|}
\hline \multirow{2}{*}{\multicolumn{7}{|c|}{ Panel A. Univariate Regression }} \\
\hline 196301 to 201812 & Cofficiont & & & & & \\
\hline 13000100201012 & Conticint & 10-1 & N-J & $\mathbf{n}=\mathbf{0}$ & $n=12$ & \\
\hline \multirow[t]{3}{*}{ EWIV } & $\mathrm{b}$ & 0.000 & 0.001 & 0.001 & 0.001 & 0.001 \\
\hline & t-stat & 0.21 & 0.34 & 0.50 & 0.34 & 0.39 \\
\hline & $R^{2}(\%)$ & -0.14 & -0.11 & -0.03 & -0.01 & 0.38 \\
\hline \multirow[t]{3}{*}{ VWIV } & $\mathrm{b}$ & -0.003 & -0.002 & -0.002 & -0.002 & -0.001 \\
\hline & t-stat & -1.32 & -1.45 & -1.28 & -1.18 & -0.77 \\
\hline & $R^{2}(\%)$ & 0.24 & 0.64 & 0.81 & 1.69 & 1.88 \\
\hline \multicolumn{7}{|c|}{ Panel B. Bivariate Regression } \\
\hline 196301 to 201812 & Coefficient & $\mathrm{K}=1$ & $K=3$ & $K=6$ & $\mathrm{~K}=12$ & $K=24$ \\
\hline \multirow[t]{3}{*}{ EWIV } & $\mathrm{b}$ & 0.014 & 0.013 & 0.012 & 0.013 & 0.011 \\
\hline & t-stat & $(2.96)$ & $(3.57)$ & $(3.58)$ & (4.07) & $(4.54)$ \\
\hline & mARM t-stat & $(2.11)$ & $(2.72)$ & $(2.43)$ & $(3.97)$ & (3.99) \\
\hline \multirow[t]{4}{*}{ VWIV } & $\mathrm{b}$ & -0.015 & -0.014 & -0.013 & -0.014 & -0.012 \\
\hline & t-stat & $(-3.03)$ & $(-3.74)$ & $(-3.68)$ & $(-4.52)$ & $(-5.13)$ \\
\hline & mARM t-stat & $(-2.62)$ & $(-3.61)$ & $(-3.66)$ & $(-3.89)$ & $(-5.09)$ \\
\hline & $R^{2}(\%)$ & 1.29 & 3.48 & 6.10 & 13.93 & 23.30 \\
\hline \multicolumn{7}{|c|}{ Panel C. Bivariate Regression with Different Sample Periods } \\
\hline 181501 to 187012 & Coefficient & $\mathbf{K}=\mathbf{1}$ & $\mathbf{K}=\mathbf{3}$ & $K=6$ & $\mathrm{~K}=\mathbf{1 2}$ & $K=24$ \\
\hline \multirow[t]{2}{*}{ EWIV } & $\mathrm{b}$ & 0.009 & 0.009 & 0.010 & 0.010 & 0.008 \\
\hline & t-stat & $(3.23)$ & $(4.69)$ & $(4.71)$ & $(4.03)$ & $(2.99)$ \\
\hline \multirow[t]{3}{*}{ VWIV } & $\mathrm{b}$ & -0.006 & -0.007 & -0.007 & -0.008 & -0.007 \\
\hline & t-stat & $(-2.13)$ & $(-3.84)$ & $(-4.20)$ & $(-3.98)$ & $(-2.81)$ \\
\hline & $R^{2}(\%)$ & 2.16 & 5.88 & 11.16 & 16.41 & 20.42 \\
\hline 187101 to 192512 & Coefficient & $\mathrm{K}=1$ & $\mathrm{~K}=\mathbf{3}$ & $K=6$ & $K=12$ & $K=24$ \\
\hline \multirow[t]{2}{*}{ EWIV } & $\mathrm{b}$ & 0.005 & 0.006 & 0.007 & 0.006 & 0.004 \\
\hline & t-stat & $(2.18)$ & $(2.54)$ & $(3.44)$ & $(3.15)$ & $(3.49)$ \\
\hline \multirow[t]{3}{*}{ VWIV } & $\mathrm{b}$ & -0.004 & -0.005 & -0.006 & -0.006 & -0.005 \\
\hline & t-stat & $(-1.79)$ & $(-2.31)$ & $(-3.43)$ & $(-3.44)$ & $(-3.49)$ \\
\hline & $R^{2}(\%)$ & 0.49 & 1.68 & 5.31 & 8.12 & 9.09 \\
\hline 192601 to 196212 & Coefficient & $K=1$ & $K=3$ & $K=6$ & $\mathrm{~K}=12$ & $K=24$ \\
\hline \multirow[t]{2}{*}{ EWIV } & $\mathrm{b}$ & 0.029 & 0.043 & 0.043 & 0.038 & 0.033 \\
\hline & t-stat & $(1.26)$ & $(2.15)$ & $(2.62)$ & $(3.42)$ & $(3.74)$ \\
\hline \multirow[t]{3}{*}{ VWIV } & $\mathrm{b}$ & -0.027 & -0.043 & -0.044 & -0.038 & -0.034 \\
\hline & t-stat & $(-1.32)$ & $(-2.46)$ & $(-2.84)$ & $(-3.50)$ & $(-3.35)$ \\
\hline & $R^{2}(\%)$ & 0.48 & 4.35 & 10.36 & 13.99 & 22.90 \\
\hline 196301 to 200112 & Coefficient & $K=1$ & $K=3$ & $K=6$ & $K=12$ & $K=24$ \\
\hline \multirow[t]{2}{*}{ EWIV } & $\mathrm{b}$ & 0.009 & 0.007 & 0.006 & 0.006 & 0.004 \\
\hline & t-stat & (3.14) & $(3.23)$ & $(2.89)$ & $(2.91)$ & $(2.49)$ \\
\hline \multirow[t]{3}{*}{ VWIV } & $\mathrm{b}$ & -0.007 & -0.006 & -0.006 & -0.006 & -0.003 \\
\hline & t-stat & $(-2.12)$ & $(-2.53)$ & $(-2.36)$ & $(-2.55)$ & $(-1.39)$ \\
\hline & $R^{2}(\%)$ & 1.29 & 3.13 & 4.83 & 10.16 & 11.38 \\
\hline 200201 to 201812 & Coefficient & $K=1$ & $K=3$ & $K=6$ & $K=12$ & $K=24$ \\
\hline \multirow[t]{2}{*}{ EWIV } & $\mathrm{b}$ & 0.023 & 0.031 & 0.032 & 0.022 & 0.014 \\
\hline & t-stat & (1.63) & $(2.38)$ & $(2.42)$ & $(2.04)$ & $(2.46)$ \\
\hline \multirow[t]{3}{*}{ VWIV } & $\mathrm{b}$ & -0.030 & -0.036 & -0.034 & -0.021 & -0.012 \\
\hline & t-stat & $(-2.16)$ & $(-2.82)$ & $(-2.65)$ & $(-1.96)$ & $(-2.48)$ \\
\hline & $R^{2}(\%)$ & 4.42 & 14.48 & 17.61 & 15.19 & 19.17 \\
\hline 181501 to 201812 & Coefficient & $K=1$ & $K=3$ & $K=6$ & $\mathrm{~K}=12$ & $K=24$ \\
\hline EWIV & $\mathrm{b}$ & 0.008 & 0.009 & 0.009 & 0.009 & 0.007 \\
\hline & t-stat & $(3.37)$ & $(4.26)$ & $(4.26)$ & $(3.92)$ & (3.24) \\
\hline VWIV & $\mathrm{b}$ & -0.009 & -0.010 & -0.010 & -0.010 & -0.008 \\
\hline & t-stat & $(-3.75)$ & $(-5.02)$ & $(-4.91)$ & $(-4.55)$ & $(-3.73)$ \\
\hline & $R^{2}(\%)$ & 0.47 & 1.65 & 3.28 & 5.56 & 7.21 \\
\hline
\end{tabular}

This table reports the results of univariate and bivariate monthly predictive regressions. The dependent variable is the average monthly valueweighted market excess returns in logarithm (MKTRF) over the relevant forecast horizon. All predictors are normalized to have zero mean and one standard deviation. K stands for the forecast horizon in number of months. "b" is the slope coefficient on the predictor. When K>1, to adjust for the overlapping dependent variable, the t-stat is computed using the GMM standard errors with K-1 Newey-West lag correction. The sample periods are specified in the table. 


\section{$10^{\text {th }}$ International Conference on Modern Research in MANAGEMENT, ECONOMICS and ACCOUNTING}

\begin{tabular}{|c|c|c|c|c|c|c|c|c|c|c|c|c|c|c|}
\hline \multicolumn{15}{|c|}{ Table 3. Multiple Predictive Monthly Regression } \\
\hline \multirow[b]{2}{*}{ Predictor } & \multicolumn{7}{|c|}{$\mathrm{K}=\mathbf{1}$} & \multicolumn{7}{|c|}{$K=12$} \\
\hline & $\begin{array}{c}\text { Control } \\
\text { b }\end{array}$ & t-stat & $\begin{array}{c}\text { EWIV } \\
\text { b }\end{array}$ & t-stat & $\begin{array}{c}\text { VWIV } \\
\text { b }\end{array}$ & t-stat & $R^{2}$ & $\begin{array}{c}\text { Control } \\
\text { b }\end{array}$ & t-stat & $\begin{array}{c}\text { EWIV } \\
\text { b } \\
\end{array}$ & t-stat & $\begin{array}{c}\text { VWIV } \\
\text { b }\end{array}$ & t-stat & $R^{2}$ \\
\hline Log dividend-price ratio & 0.002 & 0.80 & 0.015 & 3.11 & -0.016 & -3.12 & 1.38 & 0.002 & 1.34 & 0.014 & 4.18 & -0.014 & -4.43 & 16.37 \\
\hline Log dividend yield & 0.002 & 0.95 & 0.015 & 3.11 & -0.016 & -3.11 & 1.42 & 0.002 & 1.33 & 0.014 & 4.17 & -0.014 & -4.42 & 16.35 \\
\hline Dividend-payout ratio & 0.000 & -0.08 & 0.015 & 3.10 & -0.016 & -3.20 & 1.26 & 0.000 & 0.35 & 0.013 & 3.87 & -0.014 & -4.45 & 14.68 \\
\hline Book-to-market ratio & 0.001 & 0.68 & 0.016 & 3.20 & -0.016 & -3.25 & 1.35 & 0.002 & 1.27 & 0.015 & 4.52 & -0.015 & -4.82 & 16.25 \\
\hline Net equity expansion & 0.000 & -0.22 & 0.015 & 3.02 & -0.016 & -3.00 & 1.27 & 0.000 & -0.16 & 0.013 & 3.95 & -0.014 & -4.28 & 14.63 \\
\hline Treasury bill rate & -0.002 & -0.90 & 0.014 & 2.90 & -0.015 & -2.86 & 1.40 & -0.001 & -0.41 & 0.013 & 4.10 & -0.014 & -4.39 & 14.76 \\
\hline Long-term yield & -0.002 & -0.89 & 0.015 & 3.11 & -0.016 & -3.15 & 1.40 & 0.000 & -0.11 & 0.014 & 4.12 & -0.014 & -4.57 & 14.60 \\
\hline Long-term return & 0.004 & 2.20 & 0.014 & 2.86 & -0.015 & -3.03 & 2.17 & 0.001 & 2.48 & 0.013 & 4.04 & -0.014 & -4.50 & 15.24 \\
\hline Term spread & 0.004 & 2.08 & 0.012 & 2.57 & -0.013 & -2.59 & 2.14 & 0.001 & 1.23 & 0.013 & 3.99 & -0.014 & -4.34 & 15.34 \\
\hline Default yield spread & 0.002 & 0.96 & 0.014 & 3.03 & -0.015 & -3.13 & 1.47 & 0.002 & 1.70 & 0.013 & 4.00 & -0.014 & -4.52 & 16.77 \\
\hline Default return spread & 0.005 & 2.49 & 0.014 & 2.91 & -0.014 & -2.91 & 2.69 & 0.001 & 1.18 & 0.013 & 4.14 & -0.014 & -4.51 & 15.13 \\
\hline Inflation & -0.002 & -1.12 & 0.014 & 2.79 & -0.015 & -2.92 & 1.51 & -0.001 & -1.27 & 0.013 & 4.15 & -0.014 & -4.60 & 15.41 \\
\hline Average correlation & 0.003 & 1.30 & 0.014 & 2.89 & -0.015 & -2.90 & 1.64 & 0.002 & 2.01 & 0.013 & 3.82 & -0.013 & -4.14 & 16.91 \\
\hline SMV & 0.0002 & -0.11 & 0.008 & 2.85 & -0.009 & -2.33 & 1.08 & 0.004 & 3.91 & 0.007 & 3.38 & -0.010 & -4.85 & 13.65 \\
\hline ILIQ & 0.002 & 0.75 & 0.010 & 1.35 & -0.012 & -1.66 & 1.19 & 0.002 & 1.37 & 0.009 & 2.10 & -0.010 & -2.68 & 14.74 \\
\hline VRP & 0.010 & 3.68 & 0.007 & 0.91 & -0.011 & -1.32 & 6.02 & 0.001 & 1.06 & 0.016 & 3.26 & -0.018 & -4.14 & 20.39 \\
\hline IVS & 0.011 & 2.85 & 0.016 & 1.12 & -0.018 & -1.30 & 5.77 & 0.001 & 0.90 & 0.026 & 2.85 & -0.028 & -3.54 & 23.97 \\
\hline SVIX & 0.002 & 0.45 & 0.014 & 1.75 & -0.018 & -2.01 & 1.00 & 0.003 & 3.18 & 0.017 & 3.39 & -0.020 & -4.39 & 26.03 \\
\hline CAY & -0.004 & -1.93 & 0.022 & 3.47 & -0.021 & -3.57 & 1.81 & 0.001 & 0.60 & 0.012 & 3.08 & -0.013 & -3.90 & 14.88 \\
\hline Sentiment & -0.003 & -1.23 & 0.015 & 3.02 & -0.015 & -2.89 & 1.42 & -0.002 & -1.10 & 0.014 & 4.26 & -0.014 & -4.49 & 15.90 \\
\hline SII & -0.006 & -3.08 & 0.021 & 3.36 & -0.021 & -3.20 & 2.84 & -0.006 & -4.10 & 0.019 & 5.04 & -0.019 & -5.52 & 31.77 \\
\hline
\end{tabular}

This table reports the results of multivariate predictive regressions with both EWIV and VWIV and each control predictor. The dependent variable is monthly market excess returns (MKTRF) and the forecast horizon is one month $(\mathrm{K}=1)$ and one year $(\mathrm{K}=12)$. I normalize all predictors to have zero mean and one standard deviation. When $\mathrm{K}>1$, to adjust for the overlapping dependent variable, the $\mathrm{t}$-stat is computed using the GMM standard errors with K-1 Newer-West correction. The sample period is from 196301 to 201812. 
$10^{\text {th }}$ International Conference on Modern Research in

MANAGEMENT, ECONOMICS and ACCOUNTING

20-22 March, 2020

Berlin, GERMANY

\begin{tabular}{|c|c|c|c|c|c|c|}
\hline \multicolumn{7}{|c|}{ Panel A. Out-of-Sample $R^{2}$ Statistics (Monthly) } \\
\hline Predictor & Statistic & $K=1$ & $\mathbf{K}=\mathbf{3}$ & $K=6$ & $K=12$ & $K=24$ \\
\hline EWIV & OOS $R^{2}(\%)$ & -0.808 & -2.193 & -2.974 & -6.671 & -19.067 \\
\hline $198101 \sim 201812$ & z-stat & 0.77 & 0.95 & 0.71 & 0.01 & -0.36 \\
\hline VWIV & OOS $R^{2}(\%)$ & -0.431 & -1.278 & -2.895 & -8.682 & -30.728 \\
\hline $198101 \sim 201812$ & z-stat & 0.24 & 0.44 & -0.24 & -0.83 & -1.33 \\
\hline EWIV+VWIV & OOS $R^{2}(\%)$ & 1.015 & 2.363 & 5.238 & 7.888 & 8.985 \\
\hline $186001 \sim 192512$ & z-stat & 2.35 & 2.52 & 2.72 & 2.49 & 1.97 \\
\hline EWIV+VWIV & OOS $R^{2}(\%)$ & 0.640 & 2.217 & 5.459 & 11.899 & 20.579 \\
\hline $198101 \sim 201812$ & z-stat & 2.14 & 2.52 & 2.95 & 3.45 & 5.00 \\
\hline \multicolumn{7}{|c|}{ Panel B. Out-of-Sample $R^{2}$ Statistics (Daily) } \\
\hline Predictor & Statistic & $\mathrm{D}=1$ & $\mathrm{D}=\mathbf{3}$ & $\mathrm{D}=6$ & $\mathrm{D}=12$ & $D=24$ \\
\hline EWIV & OOS $R^{2}(\%)$ & -0.061 & -0.167 & -0.296 & -0.610 & -1.199 \\
\hline $19810103 \sim 20181231$ & Z-stat & 0.76 & 0.92 & 1.18 & 1.29 & 1.38 \\
\hline VWIV & $\operatorname{OOS} R^{2}(\%)$ & -0.048 & -0.121 & -0.189 & -0.363 & -0.733 \\
\hline $19810103 \sim 20181231$ & Z-stat & 0.08 & 0.12 & 0.36 & 0.48 & 0.62 \\
\hline EWIV+VWIV & $\operatorname{OOS} R^{2}(\%)$ & 0.055 & 0.154 & 0.316 & 0.654 & 1.346 \\
\hline $19810103 \sim 20181231$ & Z-stat & 2.70 & 3.01 & 3.10 & 3.12 & 3.12 \\
\hline \multicolumn{7}{|c|}{ Panel C: Optimal Portfolio Sharpe Ratio and Certainty Equivalent Return (CER) Gain (Monthly) } \\
\hline Predictor & Statistic & $K=1$ & $\mathbf{K}=\mathbf{3}$ & $K=6$ & $K=12$ & $K=24$ \\
\hline EWIV & Sharpe Ratio & 0.378 & 0.386 & 0.392 & 0.395 & 0.351 \\
\hline $198101 \sim 201812$ & CER Gain (\%) & -0.770 & -0.115 & 0.467 & 0.482 & 0.077 \\
\hline VWIV & Sharpe Ratio & 0.396 & 0.397 & 0.361 & 0.355 & 0.271 \\
\hline $198101 \sim 201812$ & CER Gain $(\%)$ & -0.090 & 0.250 & 0.196 & 0.094 & -0.618 \\
\hline EWIV+VWIV & Sharpe Ratio & 0.642 & 0.601 & 0.591 & 0.564 & 0.466 \\
\hline $186001 \sim 192512$ & CER Gain (\%) & 1.488 & 1.910 & 1.637 & 0.857 & 1.528 \\
\hline EWIV+VWIV & Sharpe Ratio & 0.497 & 0.509 & 0.514 & 0.553 & 0.414 \\
\hline $198101 \sim 201812$ & CER Gain (\%) & 1.358 & 1.928 & 2.431 & 3.272 & 1.325 \\
\hline \multirow{2}{*}{ Historical Average } & Sharpe Ratio & 0.401 & 0.377 & 0.345 & 0.350 & 0.299 \\
\hline & CER Gain (\%) & - & - & - & - & - \\
\hline
\end{tabular}

The forecast target is the market excess returns (MKTRF). The construction process is specified in section 3. The z-stat is computed based on Clark and West (2007), I reject the null hypothesis if this z-stat is greater than 1.282 (for a one-sided test at $10 \%$ confidence), 1.645 (for a onesided test at $5 \%$ confidence), or 2.334 (for a one-sided test at $1 \%$ confidence). The out-of-sample evaluation periods are specified in the table. 
$10^{\text {th }}$ International Conference on Modern Research in MANAGEMENT, ECONOMICS and ACCOUNTING

Figure 1. Monthly Time Series of EWIV and VWIV
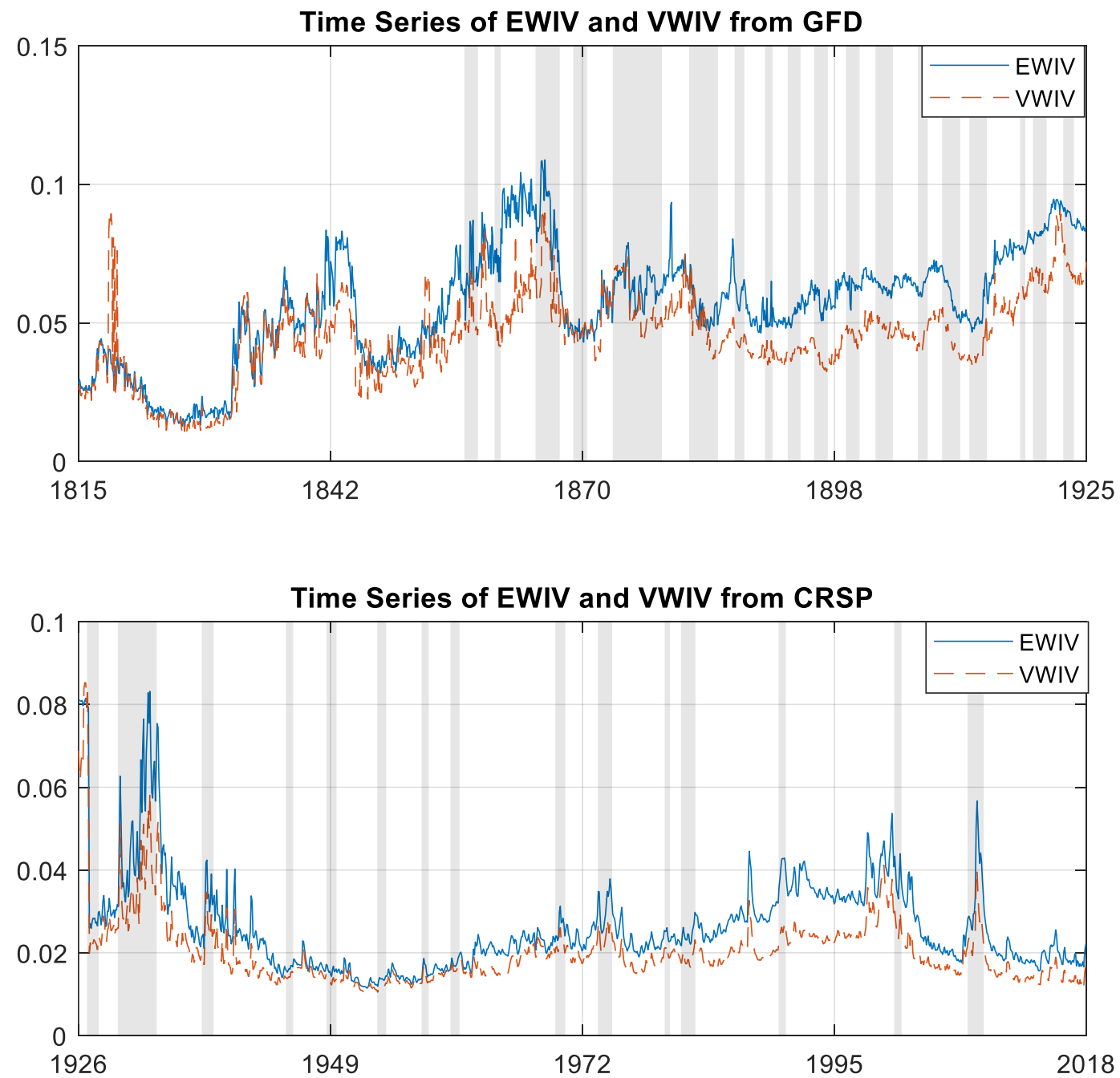

Figure 1 depicts the time series of EWIV and VWIV from 1815 to 2018. The data before 1926 is collected from Global Financial Data (GFD), while the data after 1926 is collected from CRSP. The variable frequency is at the monthly level. The grey areas indicate the National Bureau of Economic Research (NBER) recession periods. 